\title{
Atresia of the right atrioventricular orifice with atrioventricular concordance
}

\author{
DAVID F. DICKINSON, JAMES L. WILKINSON, AUDREY SMITH, AND \\ ROBERT H. ANDERSON ${ }^{1}$ \\ From Institute of Child Health, Department of Child Health, University of Liverpool; Royal Liverpool \\ Children's Hospital, Liverpool, and Cardiothoracic Institute, Brompton Hospital, London
}

SUMMARY Three hearts are described in which a fibrous membrane was interposed between the right atrium and a formed but hypoplastic right ventricle, which possessed recognisable inlet, trabecular, and infundibular components. In these hearts the distribution of the conducting tissue was as expected for concordant atrioventricular connections, and contrasts with that seen in the classical type of 'tricuspid atresia'. The distinctive morphological and histological features of these specimens lend further support to our view that the majority of cases of atresia of the right atrioventricular orifice should be regarded as coming within the designation of 'the univentricular heart'.

Opinion is divided regarding the morphology of the ventricular chambers in hearts with 'tricuspid atresia'. Bharati and her colleagues (1976) stated that the anomaly should be considered as a variant of the hypoplastic right heart complex, comparable to hearts with tricuspid stenosis and pulmonary atresia with intact ventricular septum. More recently, Bharati and Lev (1977a) have studied the conducting tissue in these hearts and used their findings in support of this opinion. By contrast, Anderson et al. (1977), while agreeing that some cases of 'tricuspid atresia' had hypoplastic right ventricles, argued that the majority were univentricular hearts, the anterior chamber being a rudimentary chamber of right ventricular type comparable to that seen in 'single ventricle with outlet chamber'. We have recently studied 3 cases of 'tricuspid atresia' associated with left juxaposition of the atrial appendages which are pertinent to this issue.

Since the description of a single case by Birmingham (1893), juxtaposition of the atrial appendages (Dixon, 1954) has been described in association with severe congenital cardiac malformations by many authors (Melhuish and Van Praagh, 1968). Atresia of the right atrioventricular orifice was present in 6 of the 21 new cases and 7 of the 21

${ }^{2}$ Robert H. Anderson is supported by the Joseph Levy Foundation and the British Heart Foundation.

Received for publication 6 July 1978 previously reported cases reviewed by Melhuish and Van Praagh (1968). Our 3 cases are of particular interest because a potential connection existed between the right atrium and a formed but hypoplastic right ventricle, in contrast to the situation in the majority of cases of 'tricuspid atresia' where the potential connection is with the 'left ventricle' (Rosenquist et al., 1970; Anderson et al., 1977).

\section{Material and methods}

The 3 specimens studied were from the pathological collections of the Royal Liverpool Children's Hospital and the Brompton Hospital, London. All died of causes related to their cardiac condition at ages ranging from 2 weeks to 2 months. After morphological study, tissue blocks, including the atrioventricular junctional area were prepared and embedded in paraffin wax. The blocks were sectioned at $10 \mu \mathrm{m}$ thickness. Initially, 1 section in 50 was stained using a modification of Masson's technique (Smith et al., 1977). Intermediate sections were prepared and examined from areas of special interest.

Reconstructions of 2 of the blocks were made by projecting the stained sections on to $6 \mathrm{~mm}$ Plastazote sheets with a magnification factor of $\times 12$. The outline was traced and cut out and the pieces coloured to identify the histological features. The pieces could then be assembled in an accurate reconstruction of the original tissue block. 


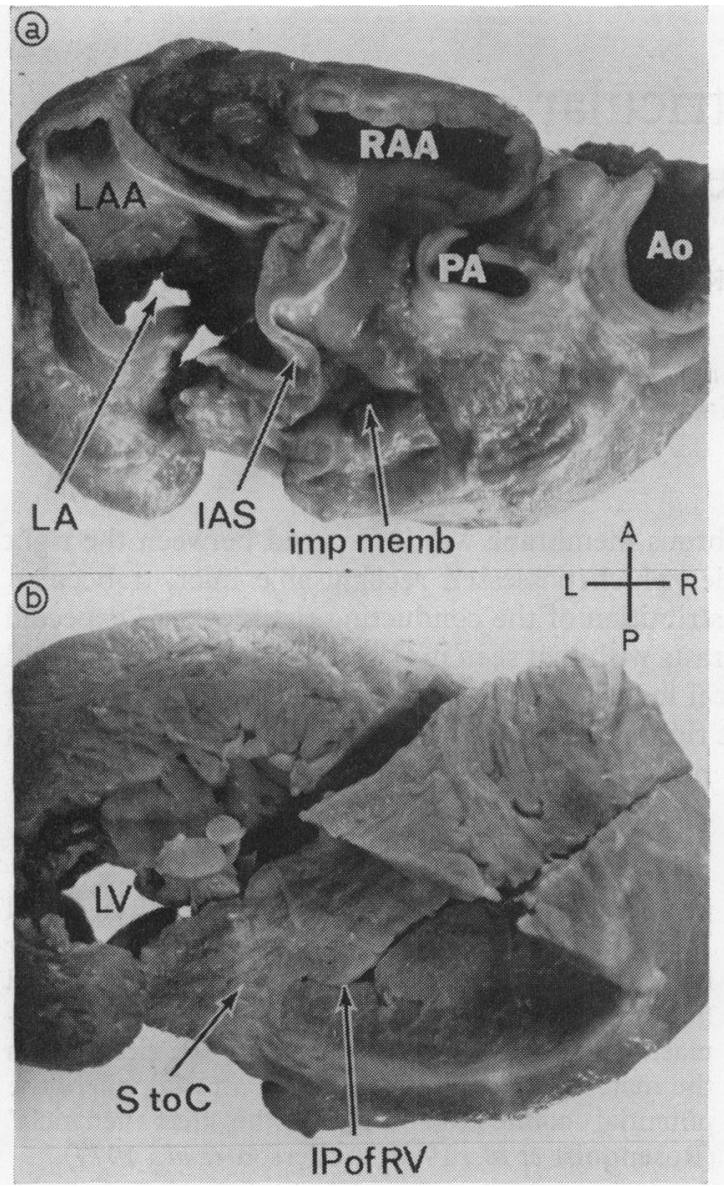

Fig. 1 (a). Case 3 viewed from above showing the floor of the right atrium and the relation of the juxtaposed atrial appendages to each other and to the great arteries. The position of the imperforate 'tricuspid' membrane is indicated (b). The ventricular mass of case 3 viewed from below. The slit-like inlet portion of the right ventricle is indicated. The picture has been reversed photographically so as to retain the same orientation as for Fig. Ia.

$P A$, pulmonary artery, Ao, aorta; $L A$, left atrium; $L V$, left ventricle; $I P$ of $R V$, inlet portion of right ventricle; $L A A$, left atrial appendage; $R A A$, right atrial appendage; IAS, interatrial septum; imp memb, imperforate tricuspid membrane; $S$ to $C$, septum to crux of heart.

\section{Results}

Visceroatrial situs solitus with laevocardia was present in all cases. The right atrium was blind ending, but in each case a discrete dimple was present in the floor of the right atrium, taking the form of a deep recess in case 3 (Fig. 1). In cases 1 and 2 , transillumination of the specimen from the ventricular mass showed an area of translucency between the main chamber and the right atrial dimple. Immediately adjacent to this was a smaller area of translucency related to the small inlet area of the right ventricle (Fig. 2).

The main ventricular chamber in all cases showed the morphological characteristics of a left ventricle, possessing an inlet via a mitral valve with paired papillary muscles. The interventricular communication was large in cases 2 and 3 but restrictive in case 1 . Its posterior margin was the area between the mitral and pulmonary valves, the pulmonary artery arising from the left ventricle in all 3 specimens. Fibrous continuity between these valves was present only in case 3. A small but discrete inlet septum extended posteriorly to the crux of the heart (Fig. 1 and 3). This arrangement is unlike the morphology of the outlet foramen seen in the majority of cases of 'tricuspid atresia'.

The small inlet portion of the right ventricle could be traced towards the right atrial dimple and possessed fine trabeculations (Fig. 1 and 3). The trabecular zone of the chamber was more coarsely trabeculated and extended down the right shoulder of the venricular mass. A smooth-walled infundibulum was present in all the hearts and supported the aorta (Fig. 3b).

The histological findings (Table) in all 3 cases confirmed that the right atrial dimple separated the atrial chamber from the right ventricle. The dimple was an imperforate fibrous membrane extending

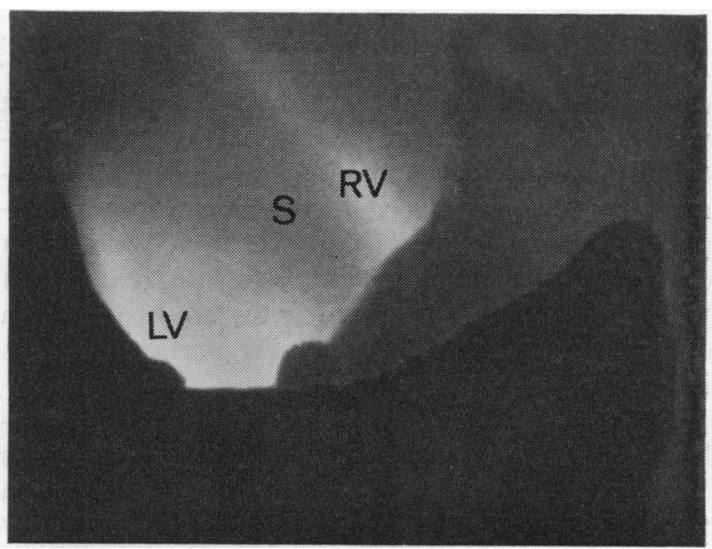

Fig. 2. View of the right atrium of case 1 when transilluminated from the ventricular mass. Two areas of translucency are seen corresponding to the inflow area of the right ventricle and the atrioventricular component of the membraneous septum separating the right atrium from the left ventricular outflow tract. $L V$, left ventricle; $R V$, right ventricle; $S$ septum. 


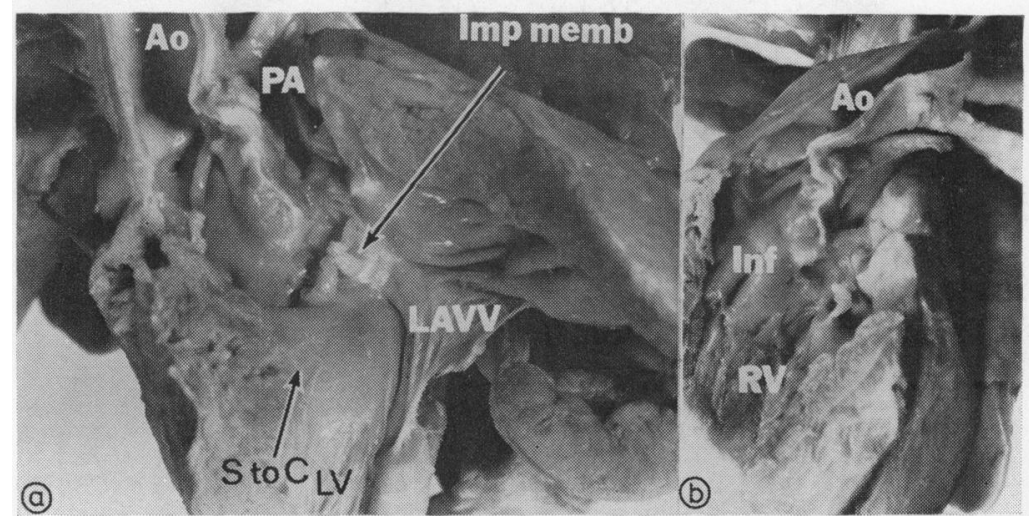

Fig. 3. (a). View of the left ventricle of case 3. The imperforate 'tricuspid' membrane is seen to the right of the smooth surfaced septum which extends to the crux of the heart. (b) View of the right ventricle of case 3 showing the hypoplastic inlet zone, a trabecular zone, and a smooth walled infundibulum, supporting the aorta. Ao, aorta; $P A$, pulmonary artery; $L V$, left ventricle; $R V$, right ventricle; Inf, infundibulum; $L A V V$, left atrioventricular valve; $S$ to $C$, septum to crux of heart; Imp memb, imperforate tricuspid membrane.

from the atrial septum to the lateral atrioventricular sulcus, and in all respects was a miniature but imperforate 'tricuspid' valve. The atrioventricular node was disposed in normal fashion in the atrial septum, with the imperforate membrane lateral to it (Fig. 4). The atrioventricular bundle penetrated at the apex of the triangle of Koch, and immediately descended on to the inlet ventricular septum, where, in cases 2 and 3, it branched into typical right and left bundle-branches (Fig. 5). In case 1 a branching bundle was not identified, the penetrating bundle being hypoplastic and merging with ventricular myocardium soon after penetrating through the fibrous anulus. Bundle-branches were identified astride the septum further anteriorly but no connection between the main bundle and either the right or left branch could be identified.

\section{Discussion}

Cases of 'tricuspid atresia' have usually been excluded by definition from the category of the univentricular heart (Van Praagh et al., 1964). This view has been challenged on angiographic grounds by Macartney et al. (1976), and on morphological grounds by Quero (1970). Lev et al. (1969) pointed to the importance of the site of the undeveloped right ventricular inlet component and its relation to the atretic right atrial orifice. Our studies have confirmed the importance of this feature. At that time Lev et al. (1969) conceded that hearts with 'tricuspid atresia' and transposition (aorta from outlet chamber) might be considered in the category of the univentricular heart, but more recently (Bharati et al., 1976), they appear to have retracted from this

Table Right atrioventricular orificial atresia with atrioventricular concordance features of conducting tissue

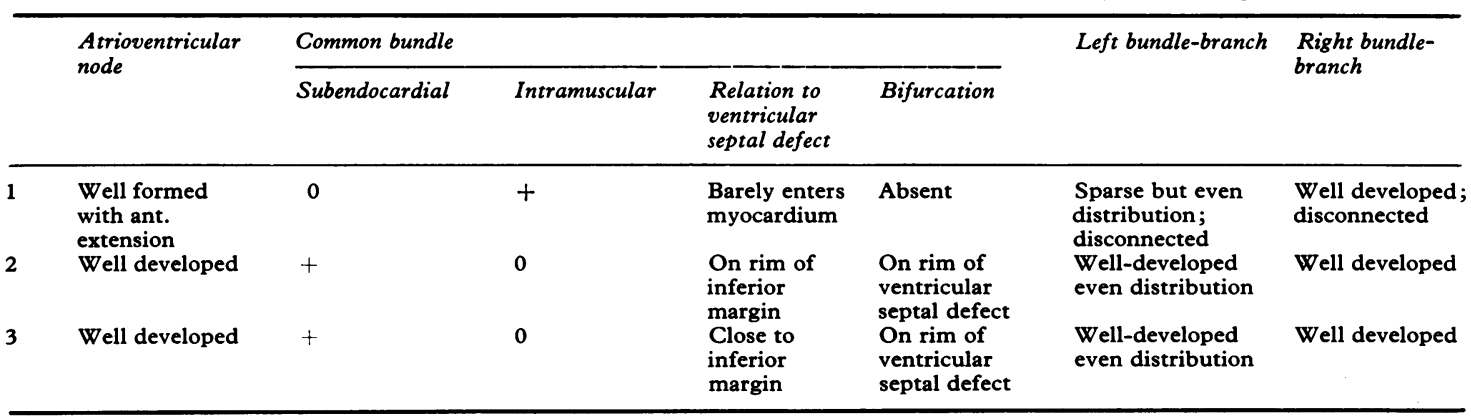

+ , present; 0 , absent. 


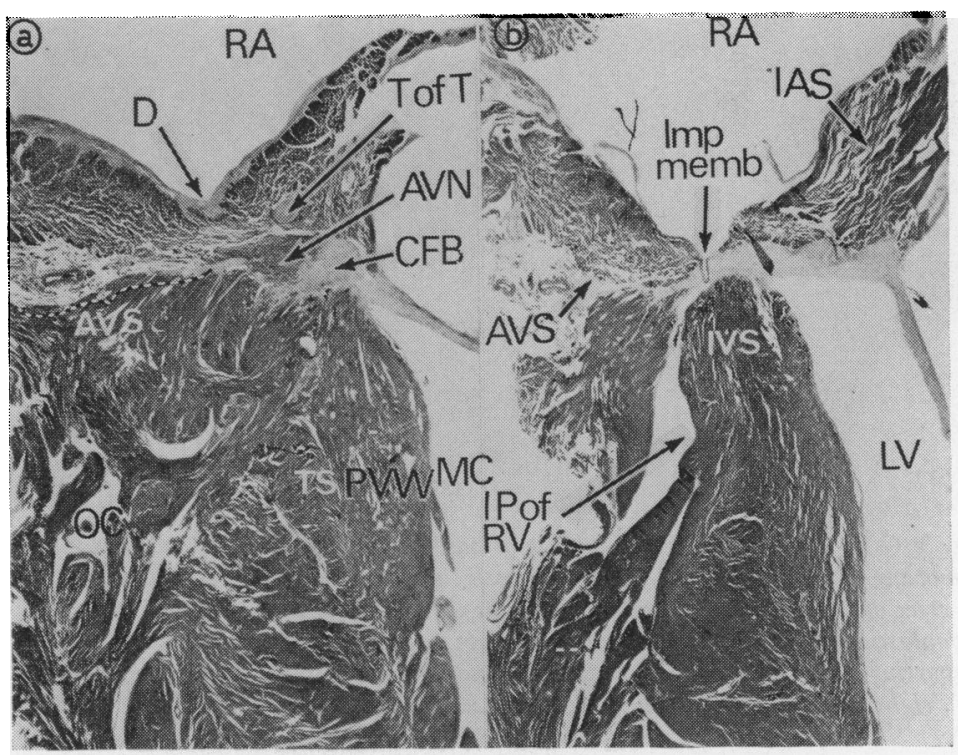

Fig. 4. (a). The histological features in a specimen with 'classical tricuspid atresia'. There is no possibility of a potential connection between the dimple in the floor of the right atrium and the anterior (outlet) chamber of the ventricular mass. (b). The histological features of case 3. An imperforate membrane is interposed between the right atrial dimple and the hypoplastic inlet portion of the right ventricle.

$R A$, right atrium; $L V$, left ventricle; $M C$, main chamber; IP of $R V$, inlet portion of right ventricle; $O C$, outlet chamber; $T$ of $T$, tendon of Todaro; $A V N$, atrioventricular node; CFB, central fibrous body; IVS, interventricular septum; $D$, dimple; Imp memb, imperforate membrane; $A V S$, atrioventricular sulcus; $P V W$, posterior ventricular wall; $I A S$, interatrial septum.

view, while still agreeing that hearts with left atrioventricular valve atresia ('tricuspid atresia' with L bulboventricular loop) would be examples of the univentricular heart. Our studies unequivocally show that in the 3 cases reported here the right atrium is in potential communication with the anterior chamber. They are not, therefore, univentricular hearts. However, in the majority of cases of right atrioventricular valve atresia, there is no potential connection between the right atrium and the anterior chamber. Indeed the blind right atrium communicates potentially with the main ventricular chamber via the atrioventricular component of the membranous septum (Rosenquist et al., 1970; Anderson et al., 1977). In this situation, our studies show that the anterior chamber has only trabecular and infundibular components and is directly comparable to the anterior rudimentary chamber seen in 'single ventricle with outlet chamber'. These hearts are, therefore, examples of univentricular hearts with absence of the right atrioventricular connection. We know of no evidence to support the view (Bharati and Lev, 1977b) that the atrioventricular orifice may be placed anywhere in this situation by secondary haemodynamic changes after the first 2 months of gestation.

The findings with regard to conducting tissue disposition (Table) are entirely in keeping with these concepts. In the cases presently described, the atrioventricular bundle is related to the inlet septum in a fashion directly comparable to that seen in isolated ventricular septal defect with atrioventricular concordance. In contrast, in examples of 'tricuspid atresia' with absent right atrioventricular connection, the ventricular conducting tissues are arranged as in univentricular hearts of left ventricular type with 2 atrioventricular valves ('single ventricle with outlet chamber') (Dickinson et al, 1979).

\section{EMBRYOLOGICAL IMPLICATIONS}

In the classical type of 'tricuspid atresia', abnormal development may be explained by failure of lateral expansion of the primitive atrioventricular canal 


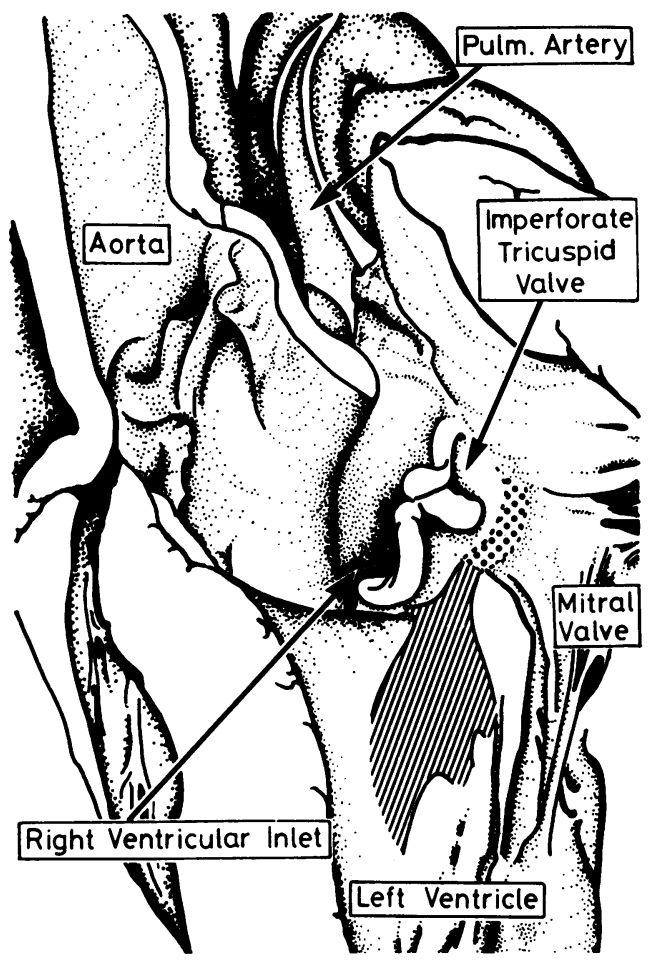

Fig. 5. Diagram of the conducting tissue in case 2 . The orientation of the specimen is as in Fig. 3a. The conducting tissue perforates the central fibrous body medial to the imperforate tricuspid membrane and lies on the posterior inferior rim of the ventricular septal defect.

with persistence of the trabecular septum in its anterior, embryonic position (Anderson et al., 1977). The embryonic bulbus therefore persists as the rudimentary chamber and the underdeveloped right atrioventricular inlet portion remains within the main ventricular chamber. However, in the present cases, rightward expansion of the atrioventricular canal has proceeded with normal alignment of atria with the two ventricles and development of the posterior inlet septum. Though the right atrioventricular inlet portion has made contact with the bulbus, the tricuspid valve has failed to develop and remains imperforate. The association, in our 3 cases, with left juxtaposition of the atrial appendages, suggests a more complex abnormality of bulboventricular looping than is usually the case in the classical type of 'tricuspid atresia'. Ventriculoarterial discordance, underdevelopment of the right ventricle, and atresia of the right atrioventricular orifice occur with considerable frequency in left juxtaposition of the atrial appendages (Melhuish and Van Praagh, 1968), and it is possible that atrioventricular concordance was present in some of the previously described cases. It is not possible to determine this retrospectively from the published reports, and, as we have shown, histological study is usually necessary to confirm atrioventricular concordance.

\section{SURGICAL IMPLICATIONS}

The observation that these cases are anatomically distinct from classical 'tricuspid atresia' is of little clinical importance, since in the described cases the right ventricular inlet component was severely underdeveloped and of little functional significance. The presence of ventriculoarterial discordance would in any case preclude the use of the right ventricle in any surgical repair, direct right atrial to pulmonary artery connection being probably the only radical reconstructive operation feasible.

Nevertheless, it is worth while re-emphasising that some cases of atrioventricular concordance with imperforate tricuspid valve have good sized right ventricles, the imperforate valve exhibiting Ebstein's malformation (Rao et al., 1973). Here the distinction between 'tricuspid atresia' with atrioventricular concordance and 'tricuspid atresia' in a univentricular heart may be of considerable importance as the right ventricle might then be surgically 'salvageable'.

\section{References}

Anderson, R. H., Wilkinson, J. L., Gerlis, M., Smith, A., and Becker, A.E. (1977). Atresia of the right atrioventricular orifice. British Heart fournal, 39, 414-428.

Bharati, S., and Lev, M. (1977a). The conducting system in tricuspid atresia with and without regular (d-) transposition. Circulation, 56, 423-429.

Bharati, S., and Lev, M. (1977b). Tricuspid atresia. Fournal of Thoracic and Cardiovascular Surgery, 74, 328-329.

Bharati, S., McAllister, H. A., jun, Tatooles, C. J., Miller, R. A., Weinberg, M., jun, Bucheleres, H. G., and Lev, M. (1976). Anatomic variations-underdeveloped right ventricle related to tricuspid atresia and stenosis. Fournal of Thoracic and Cardiovascular Surgery, 72, 383-400.

Birmingham, A. (1893). Extreme anomaly of the heart and great vessels. Fournal of Anatomy and Physiology, 27, 139-150.

Dickinson, D. F., Wilkinson, J. L., Smith, A., Becker, A. E., and Anderson, R. H. (1979). Atrioventricular conduction tissues in univentricular hearts of left ventricular type with absent right atrioventricular connection ('tricuspid atresia'). British Heart fournal, 42, 1-8.

Dixon, A. St. J. (1954). Juxtaposition of the atrial appendages: two cases of an unusual congenital cardiac deformity. British Heart fournal, 16, 153-164.

Lev, M., Liberthson, R. R., Kirkpatrick, J. R., Eckner, F. A. O., and Arcilla, R. A. (1969). Single (primitive) ventricle. Circulation, 39, 577-591.

Macartney, F. J., Partridge, J. B., Scott, O., and Deverall, P. B. (1976). Common or single ventricle: an angiographic and hemodynamic study of 42 patients. Circulation, 53, 543-554. 
Melhuish, B. P. P., and Van Praagh, R. (1968). Juxtaposition of the atrial appendages. A sign of cyanotic heart disease. British Heart fournal, 30, 269-284.

Quero, M. (1970). Atresia of the atrioventricular orifice associated with a Holmes heart. Circulation, 42, 739-744.

Rao, P. S., Jue, K. L., Isabel-Jones, J., and Ruttenberg, H. D. (1973). Ebstein's malformation of the tricuspid valve with atresia. American fournal of Cardiology, 32, 1004-1009.

Rosenquist, G. G., Levy, R. J., and Rowe, R. D. (1970). Right atrial-left ventricular relationships in tricuspid atresia; position of the presumed site of the atretic valve as determined by transillumination. American Heart fournal, 80, 493-497.
Smith, A., Ho, S. Y., and Anderson, R. H. (1977). Histological study of the cardiac conducting tissue system as a routine procedure. Medical Laboratory Sciences, 34, 223-229.

Van Praagh, R., Ongley, P. A., and Swan, H. J. C. (1964). Anatomic types of single or common ventricle in man. American fournal of Cardiology, 13, 367-386.

Requests for reprints to Dr James L. Wilkinson, Institute of Child Health, Alder Hey Children's Hospital, Eaton Road, Liverpool L12 2AP. 